\title{
a trajetória do socialismo na iugoslávia (1945-1990) ${ }^{\star}$ the trajectory of socialism in yugoslavia (1945-1990)
}

\author{
Luiz Henrique Marques Gomes $\star \star$ \\ Faculdade de Economia, Universidade Federal Fluminense, Niterói, Rio de Janeiro, Brasil
}

\begin{abstract}
RESUMO
O objetivo deste trabalho é realizar uma investigação histórica sobre a economia da Iugoslávia durante o período entre 1945 e 1990. Nesse ínterim, o país estudado reivindicou o socialismo como sistema social. Por conta disso, o enfoque da análise estará nas principais características e na evolução histórica do socialismo iugoslavo. $\mathrm{O}$ artigo consiste em uma pesquisa bibliográfica e documental com base nos dados e na literatura acerca do tema. Os resultados obtidos indicam que o socialismo de mercado iugoslavo não foi capaz de superar o processo de burocratização da economia verificada nos demais países socialistas. Para atingir seu objetivo, este trabalho divide-se em seções, as quais estão organizadas de acordo com os temas mais relevantes para a compreensão do desenvolvimento iugoslavo.
\end{abstract}

Palavras-chave: História. Economia. Europa. Iugoslávia. Socialismo.

\begin{abstract}
The objective of this work is to carry out a historical investigation about the economy of Yugoslavia during the period between 1945 and 1990. Throughout this span, the country studied had claimed socialism as its social system. Because of this, the focus of analysis will be on the key features and the historical evolution of Yugoslav socialism. The article consists of a bibliographical and documentary research based on data and literature on the subject. The achieved results indicate that, as in the other socialist countries, Yugoslavian market socialism was not able to overcome the process of economic bureaucratization. To achieve its objective, this work is divided into sections, which are organized according to the most relevant themes for understanding the development of Yugoslavia.
\end{abstract}

Keywords: History. Economics. Europe. Yugoslavia. Socialism.

* Parte deste trabalho esteve incluída na tese de doutoramento do autor (Gomes, 2017). Submetido: 11 de setembro de 2018; aceito: 16 de abril de 2019.

$\star \star$ Doutor em Economia pela Universidade Federal Fluminense. E-mail: luizhg47@, gmail.com 


\section{Introdução}

A Iugoslávia foi um país do Leste Europeu que pertenceu ao chamado campo socialista durante o período da Guerra Fria. O objetivo deste trabalho é realizar uma investigação histórica sobre a economia iugoslava durante o período entre 1945 e 1990. Nesse ínterim, o país estudado reivindicou o socialismo como sistema social. Por conta disso, o enfoque da análise estará nas principais características e na evolução histórica do regime socialista implementado no país. Com relação aos demais países do campo socialista, a Iugoslávia apresentou uma peculiaridade importante que foi o fato de que as empresas eram cooperativas administradas pelos próprios trabalhadores.

O presente artigo é uma pesquisa bibliográfica e documental que reconstrói teoricamente a trajetória das transformações socioeconômicas da Iugoslávia após a Segunda Guerra Mundial. A metodologia consiste na investigação de fontes bibliográficas e dados estatísticos para cumprir com o objetivo proposto. Sobre as fontes bibliográficas, consultamos uma série de trabalhos datados tanto da época entre 1945 e 1990, como posteriores a ela, de maneira tal que obtivéssemos o máximo de informação possível sobre a Iugoslávia. Em termos das perspectivas teóricas dos autores consultados, elas são também bastante variadas. $\mathrm{Na}$ medida do possível, tentamos trazer os autores locais à discussão e enriquecer o texto com a perspectiva dos próprios protagonistas. No que concerne aos dados estatísticos, eles foram utilizados sempre que estavam disponíveis e deu-se preferência às bases de dados dos países ocidentais em virtude dos conhecidos problemas com os dados estatísticos oriundos dos países do campo socialista.

Por fim, cabe esclarecer o uso do termo "socialismo". Muito se discute sobre a natureza do regime social existente nos países que se autodenominam socialistas. Capitalismo de Estado, socialismo, socialismo real, países em transição ao socialismo e, até mesmo, comunismo são termos usualmente utilizados para descrevê-los. Com o fim de se adequar à maior parte da literatura existente, no presente artigo designamos o regime social desses países como socialismo ou socialismo real. Note-se que essa é uma definição estritamente jurídica a qual escamoteia o caráter das relações de produção, se continuavam a ser de exploração como no capitalismo. A discussão sobre essa tema será feita em algumas passagens 
do texto, cabendo neste espaço apenas alertar para o uso que fazemos do termo "socialismo". Seguindo essa mesma linha de raciocínio, o termo "transição ao socialismo" designará o período em que ocorre a expropriação dos meios de produção das antigas classes dominantes e a sua disposição em empresas estatais e/ou cooperativas.

A hipótese investigada neste trabalho é de que as contradições econômicas, sociais e políticas do socialismo iugoslavo foram as causas principais para o decesso dele. Os resultados obtidos indicam que o socialismo de mercado iugoslavo não foi capaz de superar o processo de burocratização da economia verificada nos demais países socialistas. Acrescido a isso, o país enfrentou problemas macroeconômicos significativos em decorrência de suas especificidades econômicas, políticas e institucionais. Para atingir seu objetivo, este trabalho divide-se em seções, as quais estão organizadas cronologicamente (a primeira cobre o período entre 1945 e 1960; a segunda, entre 1960 e 1975; e a terceira, entre 1975 e 1990). Há ainda uma seção de conclusões.

\section{A reconstrução do pós-guerra e a implementação do socialismo (1945-1960)}

Nesta seção do texto vamos estudar o período entre 1945 e 1960. A Iugoslávia (que significa "terra dos eslavos do Sul”) foi criada em 1918, ao fim da Primeira Grande Guerra. Integravam esse novo Estado o Reino da Sérvia (que incluía Kosovo,Vojvodina e Macedônia) e o Reino de Montenegro, então independentes, com o Reino dos Sérvios, Croatas e Eslovenos (que incluía a Bósnia e a Herzegovina), o qual fazia parte do Império austro-húngaro. O então Reino da Iugoslávia foi invadido pelo Eixo em 1941, com a resistência antifascista, sendo liderado pelo Partido Comunista da Iugoslávia, que era chefiado por Josip Tito. Este assume o poder em 1944, depois da definitiva derrota e expulsão dos nazi-fascistas, em um governo de coalizão com distintas forças políticas. Em novembro de 1945, a Monarquia foi extinta. No ano seguinte foi promulgada uma nova Constituição e fundada a República Popular Federativa da Iugoslávia, composta por seis Repúblicas: Croácia, Eslovênia, Bósnia e Herzegovina, Sérvia, Macedônia e Montenegro (Bicanic, 1976, p. 15-19, 41, 49; Staar, 1971, p. 182-185). 
Como nas demais experiências de transição ao socialismo, os primeiros passos tomados foram a nacionalização de empresas e a reforma agrária. De início foi estabelecido um regime centralizado, hierarquicamente organizado e baseado em diretrizes administrativas para a alocação dos recursos. Ou seja, a economia foi organizada nos moldes stalinistas. Contudo, a expulsão da Iugoslávia do Kominform, e o consequente rompimento de relações entre a União das Repúblicas Socialistas Soviéticas (URSS) e a Iugoslávia, fez com que o regime tomasse novos rumos. O Kominform foi uma organização fundada em 1947 para a troca de informações entre os dirigentes do Leste Europeu, com o fim de consolidar a hegemonia da URSS sobre a região. Os soviéticos no pós-guerra buscaram estender sua influência sobre os assuntos internos da Iugoslávia, tal como fizeram nos demais países do Leste Europeu (tanto é que eles eram conhecidos como "países satélites" da URSS), porém o Partido Comunista da Iugoslávia rejeitou qualquer tipo de subordinação, já que a liberação do país foi obra da própria resistência dos movimentos sociais, e não do Exército da URSS. Além disso, Moscou posicionou-se contrariamente às intenções iugoslavas de anexar a Albânia e de se envolver na Guerra Civil da Grécia. As escaramuças se escalaram até o ponto em que a URSS expulsou o Partido Comunista da Iugoslávia do Kominform, condenando os seus membros como "revisionistas" dos princípios marxistas-leninistas (Hunt; Sherman, 1977, p. 63; OIT, 1974, p. 312-313; Perovic, 2007, p. 40-45; Staar, 1971, p. 182-185).

A expulsão dos iugoslavos do bloco soviético forçou que os seus líderes buscassem ajuda do Ocidente para a reconstrução do pós-guerra. Aos países capitalistas, notadamente os EUA, era interessante ajudar um país socialista dissidente dos ditames de Moscou, de modo a fomentar divisões e disputas no bloco soviético (durante a década de 1950, a ajuda dos países capitalistas à Iugoslávia foi de cerca de US $\$ 3,5$ bilhões). O novo caminho iugoslavo caracterizar-se-ia, no front externo, por uma política externa independente, de não alinhamento com o bloco socialista e tampouco com o bloco capitalista. Dessa forma, a Iugoslávia buscava manter certo protagonismo no cenário internacional (nos anos subsequentes o país seria considerado um dos líderes dos chamados países não alinhados) e obter negócios vantajosos com os dois blocos de países. No front interno, o país abandonaria o modelo stalinista, de modo a adotar um sistema econômico baseado na autogestão das firmas pelos 
próprios trabalhadores, e na descentralização das decisões políticas (mas não do poder político que continuaria concentrado no Partido Comunista, cujo nome, em 1952, mudou para Liga dos Comunistas) (Hunt; Sherman, 1977, p. 63; OIT, 1974, p. 312-313; Staar, 1971, p. 182-185, 210).

A estratégia adotada a partir do rompimento com a URSS, pois, foi a da descentralização das decisões econômicas, com a introdução da autogestão das firmas pelos trabalhadores, e a descentralização das estruturas políticas, com a formação de comunas, as quais organizavam o poder político local ${ }^{1}$. A ideia subjacente a essas medidas era evitar que a economia fosse governada através de medidas administrativas, mas que respondesse aos desígnios dos próprios produtores, além de evitar que as rivalidades regionais fossem atiçadas por conta da presença de um governo centralizador. No dia 27 de junho de 1950, entrou em vigor a lei que versava sobre a autogestão das empresas pelos trabalhadores, a qual dizia o seguinte:

As fábricas, minas, empresas de comunicação, de transporte, comerciais, agrícolas, florestais, comunais e outras empresas do Estado serão dirigidas, enquanto propriedade da nação, em nome da comunidade social, por coletividades de trabalhadores no âmbito do plano econômico e sobre a base dos direitos e obrigações estabelecidos pelas leis e pelos regulamentos [...]. As coletividades de trabalho assegurarão essa gestão por meio dos conselhos operários, dos comitês de gestão das empresas. (OIT, 1974, p. 312, nota 2) ${ }^{2}$

Logo, nesse país os meios de produção estatizados eram dispostos pelos próprios trabalhadores através de cooperativas, as quais eram denominadas "organizações básicas de trabalho associado". A estrutura das empresas era organizada da seguinte maneira: o conjunto dos trabalhadores de uma dada firma elegia um "conselho operário", composto por

1 Existiam quatro níveis de governo: federação, repúblicas, distritos e comunas (Fleming; Sertic, 1962, p. 202).

2 "Las fábricas, minas, empresas de comunicación, de transporte, comerciales, agrícolas, forestales, comunales y otras empresas de Estado serán dirigidas, en tanto propriedad de la nación, en nombre de la comunidad social, por colectividades de trabajadores en el marco del plan económico y sobre la base de los derechos y obligaciones establecidos por las leyes y reglamentos [...]. Las colectividades de trabajo asegurarán esta gestión por medio de los consejos obreros, de los comités de gestión de las empresas." 
cerca de 20 a 30 representantes com um mandato de 2 anos, o qual era o responsável pelas principais decisões (produção, preços, divisão do trabalho etc.). Esse conselho, por sua vez, elegia um "comitê de gestão", órgão que administrava a firma e que era formado, geralmente, por 3 a 11 membros. A composição desse comitê deveria obedecer à regra de que no mínimo três quintos de seus membros fossem trabalhadores empregados diretamente na produção. Entre os dois quintos restantes do "comitê de gestão", estaria o diretor da empresa, o indivíduo responsável pela atividade da firma diante dos órgãos de supervisão da autogestão (Hunt; Sherman, 1977, p. 64-67; OIT, 1974, p. 314; Wilczynski, 1983, p. 104-106).

Embora houvesse participação dos trabalhadores nas etapas decisórias iniciais, a autogestão iugoslava era hierarquizada e dominada por uma elite na empresa. Os conselhos operários eram dominados por gerentes profissionais e especialistas (engenheiros etc.). Os diretores das firmas detinham a prerrogativa de suspender as decisões dos conselhos operários, caso julgassem que estavam em desacordo com os interesses do Estado iugoslavo. A ascensão dos trabalhadores comuns aos "conselhos operários" e aos "comitês de gestão" era obstaculizada pelas disputas de poder internas às firmas e pela influência da Liga dos Comunistas da Iugoslávia na vida das empresas. A situação de falta de acesso às instâncias decisórias se agravava na medida em que os trabalhadores possuíam menor qualificação profissional. Por exemplo, no início da década de 1970 , os trabalhadores classificados como semiqualificados e não qualificados, os quais respondiam por $42 \%$ da força de trabalho, ocupavam somente $16 \%$ dos postos dos "conselhos operários". O mesmo quadro se repetia nas posições administrativas do Estado: na Assembleia Federal o número de delegados com a máxima qualificação profissional passou de 21\% em 1958 para 68\% em 1969; nas Assembleias das Repúblicas, o número de delegados que eram operários passou de 9\% em 1958 para apenas 1\% em 1970. Ademais, as diferenças nos salários, na apropriação dos lucros, e as regalias envolvidas com a posição ocupada na Liga dos Comunistas e no aparato do Estado aumentavam ainda mais os privilégios dessa elite iugoslava. Desse modo, em que pese existir a autogestão das firmas, na Iugoslávia foi formando-se uma casta burocrática diferenciada, a qual acumulava privilégios e que lutava por perpetuar-se no poder (Vuskovic, 1976; Wilczynski, 1983, p. 114-115). 
Um detalhe importante sobre o sistema iugoslavo era a política salarial.Até 1951, os salários eram determinados pelo governo central. $\mathrm{Na}$ transição para o novo sistema econômico baseado na autogestão das empresas, entre 1952 e 1953, o sistema utilizado era o chamado stopa akumulacije i fondova. Nesse sistema, o fundo salarial das firmas era determinado pela diferença entre o faturamento e os impostos e contribuições devidos ao governo, além de uma taxa de poupança obrigatória. Se isso não era suficiente para cumprir com os níveis básicos de vida dos trabalhadores, o governo ressarcia estes (existia um salário mínimo). O sistema salarial implantado em 1954 considerava que os salários seriam compostos de duas partes: o salário fixo, que cobriria as necessidades básicas, e o salário variável, o qual seria retirado do lucro da firma. Em 1955, foi decidido que os salários não seriam mais determinados por atos administrativos do governo, mas estariam sob responsabilidade das comunas, firmas e sindicatos. A partir de 1958, o sistema salarial foi extinto e o salário passou a depender, basicamente, do resultado final (lucro ou prejuízo) das empresas (Bicanic, 1976, p. 140-152).

No tocante ao investimento, variável-chave de política econômica, até a entrada em vigor do sistema baseado na autogestão, ele era controlado centralmente e ditado unicamente por medidas administrativas. Com o novo sistema econômico, a política de investimentos passou a ser responsabilidade não só do Estado, mas também das empresas. Estas dispunham de recursos advindos do Estado (o fundo de investimento) e da sua própria capacidade de acumulação. Como quem distribuía o fundo de investimento era o Estado, através de seus bancos, as autoridades acreditavam que fossem capazes elas de determinar a direção do desenvolvimento econômico através da alocação desse fundo para os setores estratégicos. Como veremos a seguir, esse sistema foi abandonado na reforma econômica da década de 1960 pelo aprofundamento do papel dos bancos no sistema de financiamento iugoslavo, com ênfase na independência das empresas (Bicanic, 1976, p. 164-169).

Sobre o sistema bancário, a situação na Iugoslávia era a seguinte: cada empresa possuía uma conta no banco comunal, que servia para, entre outros motivos, o pagamento entre as empresas, o controle financeiro dos bancos sobre os depositantes e a concessão de crédito pelos bancos. Este dependia não das tarefas designadas pelo plano, mas sim da credibilidade dos requerentes diante dos bancos de que iriam honrar os com- 
promissos assumidos; se as empresas não demonstrassem capacidade de solvência, o crédito só seria concedido se houvesse a garantia de que alguma instância pública honraria a dívida. A taxa de juros no sistema iugoslavo tinha um papel ativo, regulando a demanda de crédito por parte das firmas. O valor máximo legal permitido era de $12 \%$ para créditos concedidos. Nesse país, havia também a concessão de crédito aos consumidores.Até 1954 os recursos para investimentos eram concedidos pelo orçamento do Estado a fundo perdido; depois dessa data eles deveriam ser reembolsados para os bancos, de quem eram feitos os pedidos de crédito (Vuckovic, 1963, p. 363-373).

Note-se que as principais decisões econômicas estavam sob responsabilidade direta das firmas, o que tornava a Iugoslávia um caso peculiar dentre os países socialistas tradicionais, acostumados com o sistema stalinista de planificação centralizada. Por um lado, havia a descentralização do poder econômico através da autogestão dos trabalhadores organizados em cooperativas. Por outro, a planificação econômica era um misto de medidas administrativas obrigatórias e de planificação indicativa através de instrumentos mercantis, de modo tal que as firmas estavam tanto sujeitas à regulação através do mercado, como ao planejamento a priori.

Mudanças importantes aconteceram no campo socialista após a morte do líder soviético, Josef Stalin. O chamado processo de desestalinização impactou não só os países satélites da URSS no Leste Europeu, como também na Iugoslávia ocorreram mudanças importantes. Nesse país, a desestalinização fez-se sentir com o reatamento das relações diplomáticas com a URSS, em 1955. Liderados por Kruschev e Tito, reaproximações diplomáticas tiveram lugar a partir de 1954, com o reatamento de relações em 1955. Esse reatamento permitiu à Iugoslávia diminuir seus gastos com defesa e rever os aspectos militares da Aliança Balcânica, acordo firmado com a Grécia e a Turquia em 1953, porém não significou que o país voltasse a pertencer ao chamado campo socialista durante os embates geopolíticos. Tito preferiu seguir com sua política de não alinhamento, a qual possibilitava manter relações com seus vizinhos socialistas e, ao mesmo tempo, seguir com as relações diplomáticas e comerciais com os países capitalistas (Fejto, 1969, p. 40-48; Rajak, 2010, cap. 3).

Depois de 1953, a autogestão tornou-se o princípio fundamental da Constituição iugoslava. A essa altura, segundo Rudolf Bicanic (1976), o país estava envolvido em uma política de "industrialização global", a 
qual consistia em uma ordem rígida de prioridades: a indústria teria prioridade sobre a agricultura, os transportes e os demais setores da economia e, no âmbito da indústria, a indústria pesada teria prioridade sobre a indústria leve, em especial o setor de máquinas e equipamentos. O produto bruto nacional cresceu anualmente, em média, $8,8 \%$ durante o período 1952 a 1956, ultrapassando a cifra correspondente para o quinquênio anterior, a qual foi de $2,4 \%$. O produto da indústria de construção de máquinas, entre 1939 e 1955, cresceu em 800\%; a produção de energia, em 250\%; e a produção de bens manufaturados, em 170\%. O produto agrícola, por sua vez, permaneceu inalterado durante o período, evidenciando a prioridade dada ao setor industrial (Bicanic, 1976, p. 102, 108-109; Vanek, 1963, p. 556).

A fase de "industrialização global" durou até 1955. Nesse período, o índice de concentração industrial foi elevado (o número de firmas industriais diminuiu de 3.110 para 2.091 entre 1938 e 1952) e os recursos do Estado para investimento foram concentrados na criação, na manutenção e na melhora da infraestrutura do país (ferrovias, barragens, centrais elétricas, novas minas etc.) e na indústria de defesa (especialmente até a morte de Stalin). O período seguinte, denominado por Bicanic (1976) de "industrialização acumulativa", era caracterizado pela descentralização industrial e pelo fim da prioridade às indústrias pesadas. A partir de então, o critério foi de dar prioridade para as indústrias que conseguissem acumular recursos no menor tempo possível, sendo capazes de, assim, financiarem o desenvolvimento de indústrias nascentes. Por isso é que seria uma "industrialização acumulativa". Desse modo, o setor prioritário da economia iugoslava, a partir de 1955, foi o setor de produção de bens de consumo, pois seria este o setor capaz de acumular recursos rapidamente. Outra característica do período foi a descentralização da atividade industrial, política desenvolvida a partir da alocação do fundo central de investimento às áreas atrasadas, de modo que o desenvolvimento das forças produtivas do país se harmonizasse e que existisse uma classe operária significativa em todas as regiões. No período entre 1956 e 1960, a média de crescimento do produto bruto nacional foi de 12,6\% por ano (Bicanic, 1976, p. 109-115; Vanek, 1963, p. 556).

Outro ponto importante sobre a transição ao socialismo da Iugoslávia foi o setor agrícola. A partir da reforma agrária de 1945, houve a intenção de fomentar a criação de cooperativas e fazendas estatais no 
campo, em termos parecidos com a agricultura soviética. Como nos demais países do Leste Europeu, o governo buscava que os agricultores aderissem à agricultura socialista através de entregas compulsórias e gravames elevados aos seus ganhos privados. Esse esforço de mudança na agricultura enfrentou uma severa resistência dos camponeses de modo tal que em 1951 apenas 39\% da área agricultável estava ocupada pelo setor socialista da agricultura. Dentro do cenário de distanciamento do modelo stalinista tradicional, uma nova política concernente o setor agrícola foi aprovada em dezembro de 1951. Com essa legislação foi estabelecido que as cooperativas seriam independentes do Estado e administradas pelos próprios trabalhadores e que a remuneração dos trabalhadores pertencentes às cooperativas seria por trabalho realizado. Dessa maneira, os iugoslavos marcavam uma distância cada vez maior com o modelo soviético. Os agricultores, por sua vez, preferiram sair das cooperativas e se dedicar à agricultura privada. A partir de 1953, o governo iugoslavo extinguiu as entregas compulsórias de produção e liberou o mercado agrícola dos controles que ainda restavam. O número de cooperativas caiu de 7.012 em 1951 para 688 em 1955. Esse movimento de fuga em direção à economia privada não foi diferente no que diz respeito às fazendas estatais, as quais reduziram gradualmente sua presença no campo iugoslavo, durante a década de 1950. Em 1955, inclusive, 286 fazendas estatais localizadas na Sérvia foram declaradas falidas pelo governo. Diante desse quadro, o governo iugoslavo passou a implementar "cooperativas agrícolas gerais", as quais eram um conjunto de agricultores atuando com maquinaria estatal e canais de crédito comum. Contudo, isso não foi capaz de alterar o fato de que a propriedade privada era a forma de propriedade predominante na agricultura iugoslava (e assim seria até o final da história do país) (Miller, 1989, p. 502-505;V. M., 1958, p. 80-87).

Em resumo, nesta seção do texto estudamos as mudanças pela qual a economia da Iugoslávia passou durante a segunda metade da década de 1940 e na década de 1950. Investigamos a implementação do socialismo no país e as alterações na trajetória de desenvolvimento da Iugoslávia decorrentes do processo de desestalinização.Vimos ainda como foi conduzido o processo de industrialização do país e de reestruturação da agricultura. 


\section{Reformas econômicas e administrativas (1960-1975)}

Nesta seção do texto, vamos estudar o período entre 1960 e 1975. A Iugoslávia passou por importantes transformações nas décadas de 1940 e 1950, com a vitória sobre o nazi-fascismo e com o estabelecimento de um regime socialista independente da União Soviética e baseado na autogestão dos trabalhadores. Contudo, as mudanças estruturais e a rápida expansão econômica do após-guerra não impediram que florescessem as primeiras dificuldades da organização do país já em meados da década de 1950.

A denúncia de Milovan Djilas (Djilas, 1957) de que havia aparecido uma nova classe dominante que conduzia o socialismo iugoslavo rumo a uma progressiva burocratização das relações sociais foi o primeiro indício de que, malgrado os bons indicadores nas esferas econômicas e sociais, o "modelo iugoslavo" não se diferenciava fundamentalmente dos regimes originados do stalinismo soviético. Recordemos que as principais características do dito "modelo stalinista" eram a condução da vida social por um estrato social diferenciado que possuía privilégios na esfera da distribuição e do consumo e a presença de relações opressivas na esfera do trabalho, o que caracterizava que as relações de produção não eram qualitativamente distintas das existentes no modo de produção capitalista. As empresas no "modelo stalinista" eram organizadas através dos princípios da direção única e do centralismo democrático.

O "modelo iugoslavo", por sua vez, distinguia-se pela organização das unidades produtivas através de cooperativas dirigidas pelos próprios trabalhadores e pelo caráter predominantemente indicativo, em vez de diretivo, da planificação econômica, o que caracterizaria o "modelo iugoslavo" como um tipo de "socialismo de mercado". É aqui justamente em que estava um sério problema da experiência iugoslava: o mercado possui uma legalidade própria cuja subordinação a objetivos sociais, se é que seja possível, depende da presença de algum tipo de planificação e coordenação global dos ramos da economia. A inexistência da coordenação ex ante do trabalho das cooperativas fazia com que elas se confrontassem no mercado como antagonistas em busca do interesse próprio, e não como partes importantes de uma divisão de trabalho nacional que organizasse as necessidades e potencialidades de cada região do país.

Esse fato é uma das causas para que a Iugoslávia vivenciasse uma série 
de desequilíbrios macroeconômicos durante sua história, como inflação e desemprego, pois a atividade das empresas estava entregue maioritariamente à anarquia de mercado (teoricamente, em uma economia planificada problemas como a variação abrupta do produto e dos preços, bem como o desemprego estrutural, inexistiriam). Se no caso do "modelo stalinista" era a arbitrariedade dos burocratas que decidia sobre a atividade econômica dos produtores, no caso do "modelo iugoslavo", em última instância, eram as leis cegas do mercado que decidiam a sorte dos produtores (Mandel, 1994). Como veremos a seguir, esse caráter mercantil do socialismo iugoslavo será acentuado após o abandono definitivo da planificação centralizada em 1965.

No fim da década de 1950 e começo da década de 1960, as dificuldades do "modelo iugoslavo" estimularam a intensificação dos debates acerca de mudanças no sistema econômico do país. Grosso modo, existiam duas correntes principais: os defensores do statu quo e os críticos. Entre os primeiros estavam os que defendiam apenas mudanças incrementais e/ou reformas administrativas a fim de acomodar os interesses das diversas Repúblicas. Os principais teóricos pertencentes a esse grupo foram Branko Horvat e Edvard Kardelj. Entre os críticos, o destaque ficava com o grupo dos humanistas, que se concentravam em torno da revista Práxis e envolvia nomes como Gajo Petrović, Mihailo Marković e Predrag Vranicki. Estes, influenciados pelos manuscritos econômicos e filosóficos que Marx escreveu em Paris, na década de 1840, insistiam na importância de que a construção do socialismo fosse a construção de uma sociedade que superasse a alienação (Gligorov, 1998).

O cenário em que se desenvolviam os debates era de uma Iugoslávia em desaceleração do ritmo de crescimento econômico, com aumento da capacidade ociosa, do desemprego, da inflação (a ponto de que muitas empresas tinham problemas de liquidez) e do deficit na balança comercial. Além disso, a Iugoslávia tomava frequentemente empréstimos dos americanos (McFarlane, 1969, p. 111-115). A solução dos iugoslavos para essa crise foi a de reforçar o caráter mercantil do sistema econômico, com uma reforma em 1965, transformar a moeda nacional (dinar) em moeda convertível e liberar a emigração em 1964, de forma que os desempregados encontrassem trabalho em outro país ${ }^{3}$ (os principais

3 As divisas remetidas pelos emigrantes tornaram-se importante fonte de financiamento 
destinos de emigração foram Alemanha Ocidental ${ }^{4}$, Holanda, Áustria e Suíça).

A reforma de 1965 visava transformar esse quadro negativo. A reforma (bem como a nova Constituição do país de 1963) reafirmou a autogestão como principal característica do sistema socioeconômico do país. Os reformistas diziam que ela possuía quatro eixos ("os quatro Ds" como ficou conhecido): descentralização (reforçar o sistema de decisão policêntrico), desestatização (desenvolvimento da autogestão em todos os setores da economia, inclusive a saúde e a educação), despolitização (diminuir a influência da Liga Comunista Iugoslava nos assuntos econômicos) e democratização (incrementar a autodeterminação e a independência das unidades econômicas). De qualquer maneira, em que pese o palavreado engenhoso dos reformistas, as principais medidas concretas foram o abandono definitivo da planificação centralizada diretiva e o aumento da liberdade das empresas (Bicanic, 1976, p. 100, 284-285).

Quanto ao abandono do planejamento diretivo, a partir da reforma de 1965, o plano econômico nacional deixou de ter qualquer tipo de medida imperativa, limitando-se a uma análise das tendências resultantes do desenvolvimento econômico e social e colocando em evidência as carências e necessidades do país. Ele era discutido no marco de reuniões entre os representantes do órgão central de planejamento, nacional e das Repúblicas, e as associações de empresas. Para a realização dos objetivos do plano, o Estado iugoslavo lançaria mão dos instrumentos clássicos de política econômica: política fiscal, política monetária, regulamentação do setor externo etc. De qualquer modo, o governo central ainda manteria um importante papel na redistribuição de recursos das regiões mais abastadas para as mais pobres e na execução de investimentos em infraestrutura (Marczewski, 1975, p. 121-122).

das contas externas da Iugoslávia: até 1970, cerca de US\$1.300 milhões haviam sido remetidos. Pela legislação do país, as pessoas físicas que possuíssem divisas estrangeiras teriam direito a uma conta corrente especial, com remuneração de $6 \%$ a 7,5\% nos bancos do país. Os efeitos da emigração sentiram-se rapidamente: se, no começo de 1967, cerca de 109 mil iugoslavos possuíam esse tipo de conta (com um valor total de US\$ 35,5 milhões), em março de 1971, 685 mil iugoslavos possuíam essa conta (com depósitos no valor de US\$ 328 milhões) (Baucic, 1972, p. 21-22).

4 Em 1970, na Alemanha Federal existiam cerca de 400 mil iugoslavos como Gastarbeiters (trabalhadores estrangeiros “convidados”) (Mihajlovic, 1987, p. 189). 
No que diz respeito à liberdade das firmas, a partir da reforma de 1965, as empresas ganharam maior espaço para decidir sua produção, escolher seus clientes e fornecedores, determinar seus investimentos, tomar empréstimos bancários e arcar com o destino dos seus negócios, inclusive no caso de uma eventual falência. $O$ sistema de fixação de preços foi flexibilizado, com as firmas conquistando margem de manobra para determinar a seu bel-prazer os preços; contudo, nesse caso a intervenção do Estado, por exemplo, através de tabelamentos e congelamentos, era mais comum, em especial em momentos de alta inflação. As empresas poderiam também fazer parte de associações ou uniões, porém era facultativa a elas essa decisão. Inclusive, elas eram permitidas a participar de mais de uma associação de firmas. Ao Estado caberia intervir em uma empresa apenas no caso de infrações às leis do país, como, por exemplo, a venda dos meios de produção confiados pelo Estado. As firmas foram habilitadas a emitir títulos e ter participações no capital de outras empresas, bem como foram liberadas para aceitar a participação de capitais estrangeiros, desde que não ultrapassasse os 49\% do capital total (Dyker, 1990, p. 65-66; Marczewski, 1975, p. 122-123).

Com a reforma de 1965, houve a diminuição da parte da renda líquida das empresas retida pelo Estado (que entre 1961 e 1964 esteve, em média, em 54\%), de forma que, após essa reforma, as empresas passaram a não mais pagar impostos sobre a renda líquida e o lucro, bem como foram retiradas as restrições que existiam sobre a utilização do lucro entre distribuição para renda pessoal e retenção para outros propósitos. Isso ocasionou, de imediato, um aumento da renda pessoal, pois as cooperativas passaram a destinar a maior parte dos lucros para a distribuição pessoal, e não para a retenção com o propósito de viabilizar investimentos futuros nas próprias firmas. Esse fato agravou o problema de inflação (pois aumentou a demanda pelos bens de consumo disponíveis sem um crescimento correspondente da oferta), além de diminuir os recursos disponíveis para os bancos, acarretando uma crise de liquidez. A solução do governo foi adotar uma política monetária restritiva a fim de contornar a situação e introduzir novamente a normalidade no sistema bancário. O resultado dessa política foi que a inflação passou de 18\% em 1966 para 3\% em 1967 e 4\% em 1968. Um detalhe importante é que, com as reformas de 1965, os bancos deixaram de ser propriedade do Estado, passando, também eles, a ser cooperativas (empresas sob 
regime de autogestão pelos próprios trabalhadores). No caso, eles eram financiados pelas empresas, pelas uniões de empresas e pelos governos de Repúblicas, e não pelo governo central. Tal como às empresas, aos bancos foi permitido emitir títulos e tomar empréstimos externos. O Estado reteve apenas poderes que obrigavam essas entidades a seguir a política monetária do Banco Nacional iugoslavo. Além de tudo isso, a reforma de 1965 promoveu uma desvalorização do câmbio oficial (Bicanic, 1976, p. 284-288; Marczewski, 1975, p. 123).

De partida, as reformas não conseguiram alterar a situação da economia iugoslava. Até 1969, com exceção de 1966, o ritmo de crescimento não ultrapassou os 5\%, o que era um fato comum na década de 1950 . Além disso, o quadro que se seguiu foi de permanência do desemprego e aumento da desigualdade social, o que culminou em protestos populares e greves, especialmente em 1968. Entre 1965 e 1973, a taxa de crescimento média da renda nacional iugoslava foi de $5,27 \%$, sendo que a média de crescimento do produto industrial foi de $6,2 \%$ e do produto agrícola foi de 2,35\% (Dyker, 1990, p. 92).

As reformas que consolidaram o "socialismo de mercado" iugoslavo e a abertura do país ao exterior favoreceram as regiões com maior tradição de engajamento no comércio exterior e no turismo, nomeadamente a Croácia e a Eslovênia. Com isso, as elites dessas Repúblicas passaram a demandar uma maior autonomia diante do governo central a fim de reter nas próprias regiões os recursos advindos do exterior. Em particular, na Croácia, as tensões entre os croatas e o governo central escalaram-se rapidamente e culminaram na chamada "Primavera Croata" de 1971. Esse evento foi uma série de protestos da população e da casta burocrática da Croácia, os quais foram reprimidos pelo aparato repressivo federal, resultando em um expurgo na Liga dos Comunistas da Croácia e na prisão de mais de 500 pessoas (Gruenwald, 1982; Samary, 1995, p. 53-54).

No início da década de 1970, a Iugoslávia passou por mudanças em seu sistema político e administrativo. Em 1974, foi promulgada uma nova Constituição, em substituição à antiga de 1963. Nessa carta foi introduzido um sistema de eleição em que se fariam representados nos órgãos legislativos seis grupos de interesses, cujos membros poderiam ser substituídos a qualquer tempo conforme deliberação de sua base eleitoral. Esses grupos eram: trabalhadores das empresas cooperativas; camponeses; profissionais liberais; funcionários do Estado, oficiais da 
Liga Comunista da Iugoslávia e soldados; representantes das comunas (que eram unidades administrativas territoriais); e membros de organizações sociais e políticas. O sistema administrativo teve seu caráter de Federação reforçado, de modo que, entre outras coisas, a intenção das elites locais em preservar seus privilégios fosse realizada. $\mathrm{O}$ fato de que muitas vezes o interesse dos grupos locais estava em oposição aos interesses da Iugoslávia quando analisado o país como um todo foi relegado a um segundo plano diante da necessidade dos dirigentes centrais em conciliar os interesses dos distintos grupos regionais (Burg, 1986; Singleton, 1985, p. 260-264). O autor Steven Burg comenta esse aspecto das mudanças postas em marcha na Iugoslávia:

As reformas políticas adotadas durante o início da década de 1970 transferiram uma quantidade enorme de poder para as lideranças regionais. Elas criaram um processo de tomada de decisão federal que requer um consenso inter-regional para a adoção das decisões mais importantes, desse modo concedendo um veto efetivo sobre a política federal para cada uma das Repúblicas e províncias. Ao mesmo tempo, contudo, os interesses políticos e econômicos das regiões continuaram a divergir. As mais desenvolvidas Repúblicas setentrionais continuaram a desfrutar de um padrão de vida mais alto, a manter níveis de produtividade e de capital também mais altos e a receber a maior parte das receitas de moedas convertíveis do país, dessa forma sendo capazes de manter rácios dívidas-lucros menores. Nas regiões subdesenvolvidas meridionais, as dívidas externas atingiram níveis que excederam significativamente as capacidades de gerar lucro das economias locais, projetos mal escolhidos e custosos consumiram proporções relevantes dos fundos de desenvolvimento e contribuíram para rácios capital-produtos menores, e o padrão de vida declinou, resultando no alargamento da distância econômica entre o Norte e o Sul. Assim, qualquer política desenhada a abordar os problemas em uma base nacional - i.e., uma base de todo o país poderia certamente engendrar custos mais altos para uma ou mais das regiões e, portanto, a oposição de suas lideranças. (Burg, 1986, p. 176) ${ }^{5}$

5 "The political reforms adopted during the early 1970s had transferred enormous power to the regional leaderships. They created a federal decision-making process that requires inter-regional consensus for the adoption of major decisions, thereby granting an effective veto over federal policy to each of the republics and provinces. At the same time, however, the political and economic interests of the regions continued to diverge. The more developed northern republics continued to enjoy higher standards of living, to maintain higher levels of capital and labour productivity, 
Dessa maneira, as mudanças na Iugoslávia terminaram por dificultar a capacidade dos governantes centrais em estabelecer uma política que enfrentasse os problemas do país como um todo. A intenção da nova Constituição era justamente fortalecer o poder das elites regionais e enfraquecer o poder do governo central de modo a apaziguar as disputas entre os distintos grupos pela administração nacional. O detalhe importante a realçar é que a descentralização do poder do país não foi sinônimo de democratização. $O$ poder efetivo era exercido pela casta burocrática pertencente à Liga Comunista da Iugoslávia e incrustada no aparato do Estado. Os trabalhadores participavam da administração através da eleição dos conselhos operários nas cooperativas, porém não possuíam voz ativa nas questões políticas e muito menos nas decisões mais importantes sobre a organização social e econômica das províncias autônomas, das Repúblicas e da própria Iugoslávia (Denitch, 1990, p. 53).

Nesta seção vimos que ocorreram reformas econômicas em meados da década de 1960, as quais reforçaram o caráter mercantil do socialismo iugoslavo. As reformas não conseguiram solucionar os principais apuros macroeconômicos que se originavam justamente dos problemas provocados pela pulverização da propriedade e pela ausência de um planejamento global. Em 1974 foi promulgada uma nova Constituição que objetivava apaziguar a crescente rivalidade entre as Repúblicas e adequar a legislação do país à situação econômica consolidada pelas reformas.

\section{O ocaso do regime socialista iugoslavo (1975-1990)}

As mudanças no cenário internacional da década de 1970 afetaram a economia da Iugoslávia de modo significativo. Nesse país, as décadas de 1970 e 1980 foram de instabilidade econômica e política (especial-

and to earn the lion's share of the country's convertible currency income, thereby enabling them to maintain lower debt-to-earnings ratios. In the underdeveloped southern regions, the external debts reached levels that far exceeded the earning capacities of the local economies, ill-chosen and costly projects consumed significant proportions of development funds and contributed to lower capital-output ratios, and the standard of living declined, resulting in a widening of the economic gap between north and south. Thus any policy designed to address problems on a national - that is, country-wide-basis would be sure to engender high costs for one or more regions and, therefore, the opposition of their leaderships." 
mente após 1980). As principais dificuldades econômicas enfrentadas diziam respeito ao desequilíbrio externo, ao desemprego e à inflação. Veremos a seguir como os problemas políticos, econômicos e sociais contribuíram para o fim do socialismo no país.

O choque do petróleo em 1973 e a recessão global que se seguiu impactaram negativamente a economia iugoslava. Os canais de transmissão da crise internacional foram majorados pela dependência energética do país e pelo grau de abertura do setor externo. Em 1974, por exemplo, o deficit comercial do país aumentou em 22\%. A taxa de crescimento caiu de 8,4\% em 1974 para 3,6\% em 1975 e o ritmo de crescimento industrial decresceu de $11 \%$ em 1974 para 6,6\% em 1975 e 3,6\% em 1976. Por outro lado, a taxa de crescimento industrial foi superior à taxa de crescimento da produtividade industrial durante o período entre 1973 e 1981, indicando que as reformas da década de 1960 não tiveram um efeito duradouro no aumento da produtividade da indústria (Dyker, 1990, p. 91-92; Woodward, 1995, p. 251-252).

Com a crise internacional, o acesso à exportação dos produtos iugoslavos para os países ocidentais foi restringido, apesar dos esforços dos dirigentes para aprofundar a aliança da Iugoslávia com os países capitalistas (por exemplo, em 1971 houve a liberação dos investimentos estrangeiros). O deficit comercial do país que foi de US\$1,2 bilhão em 1973 saltou para US\$3,1 bilhões em 1974. Barreiras não tarifárias contra carne, aço, têxteis e navios iugoslavos foram aplicadas (por parte dos países da Europa Ocidental) em meados da década de 1970, dificultando uma melhora significativa desse saldo (deficit de US \$2,9 bilhões em 1975 e de US $\$ 1,7$ bilhão em 1976). A balança de transações correntes seguiu o mesmo caminho, com saldos negativos em 1974 e 1975 (US\$ 1,26 bilhão em 1974 e US\$ 925 milhões em 1975). A tentativa de ajuste dessa situação foi através de flexibilização e desvalorização do câmbio e uma mudança no destino do comércio externo, dos países em que o comércio era feito através do uso de divisas aos países que aceitavam os acordos bilaterais de balanço mútuo (clearing accounts). As exportações para os países da OCDE (Organização para a Cooperação e Desenvolvimento Econômico) caíram de uma média de 55,2\% do total das exportações iugoslavas no período 1971-1973 para 40,5\% no período 1974-1978; as exportações para os países do COMECON (Conselho para Assistência Econômica Mútua), por sua vez, passaram de 35,6\% em 
1971-1973 para 43\% no período 1974-1978 (Neuberger; Tyson, 1980, p. 164; Woodward, 1995, p. 251-252).

Além da mudança do destino do comércio, a falta de divisas do país foi combatida através do endividamento externo. A partir do choque do petróleo, a liquidez internacional aumentou consideravelmente e os dirigentes iugoslavos aproveitaram-se desse fato como fonte de recursos. Além disso, tomaram empréstimos com o Banco Mundial, tornando-se um importante cliente do banco (em 1977-1978 os empréstimos dessa instituição chegaram a US $\$ 750$ milhões), e promoveram acordos do tipo joint ventures, em especial na área de energia e petroquímicos. Em 1975, os bancos foram liberados para tomar empréstimos em divisas no exterior. Em 1977, a mesma permissão foi concedida às empresas do país. A demanda por empréstimos no chamado euromercado ${ }^{6}$ (euromarket ou eurodollar market, em inglês) por parte das empresas iugoslavas foi significativa, a ponto de que alguns dos principais bancos europeus reclamassem ao governo iugoslavo que organizasse o pedido de empréstimos (Woodward, 1995, p. 252-253).

Diante de tal quadro, o endividamento externo da Iugoslávia apresentou um considerável aumento durante o período em estudo. Entre 1969 e 1982, em um espaço de 13 anos, a dívida externa aumentou de US\$ 2 bilhões para US\$2 20 bilhões, ou seja, um aumento de 900\%. Diante do segundo choque do petróleo em 1979 e o aumento na taxa de juros nos EUA, o financiamento das contas externas tornou-se cada vez mais dificil (se, em 1979, o serviço da dívida consumia US $\$ 1,8$ bilhão, em 1981 subiu para US\$2,9 bilhões) e o país se viu na posição de recorrer a empréstimos do FMI novamente (já havia feito o mesmo na década de 1960 e em 1971). Entre 1981 e 1983 foram liberados créditos do FMI no valor de US\$1,8 bilhão. A contrapartida do empréstimo seguiu a cartilha do Fundo: política monetária e creditícia restritiva, depreciação da taxa de câmbio real, aumento das taxas de juros, ajustes de preços e limites na expansão dos gastos públicos, além da obtenção de divisas através de um esforço exportador. Um processo de renegociação da dívida também teve lugar a essa altura.Além disso, um empréstimo de US $\$ 2$ bilhões foi obtido, em janeiro de 1983, através de negociações organizadas pela Embaixada dos EUA e pelo Departamento de Estado

6 Eurodólares são depósitos em dólar norte-americano fora dos EUA. 
desse país, com o próprio FMI, o Banco Mundial, o BIS (Banco da Basileia), 15 países ocidentais e 600 bancos comerciais capitalistas. Esses países, conhecidos na literatura como "Amigos da Iugoslávia”, condicionaram o refinanciamento aos ajustes de austeridade e às reformas pró-mercado, porém não a mudanças políticas. Um segundo empréstimo exclusivo com o FMI, no valor de US\$ 400 milhões, seria concretizado em abril de 1984. Tais medidas, contudo, não impediram que, entre 1983 e 1986, o custo do serviço da dívida crescesse e chegasse ao montante de US\$ 5 bilhões por ano (Crnobrnja, 1996, p. 85; DOI, 1984, p. 7; Lampe; Prickett;Adamovic, 1990, p. 180; Singleton, 1985, p. 268; Woodward, 1995, p. 252-255).

Além da dívida externa, um dos problemas relevantes da economia iugoslava era o desemprego. A recessão de 1975 e 1976 na Alemanha Ocidental fez com que retornassem milhares de iugoslavos emigrantes, agravando a pressão sobre o nível de desemprego. A taxa de desemprego passou de 9,1\% em 1973 para 13,9\% em 1977, chegando a 16,3\% em 1985. O número de trabalhadores emigrantes, que atingiu um pico de 860 mil pessoas em 1973, diminuiu gradualmente a partir de 1974, chegando a 770 mil em 1975, 695 mil em 1978 e 650 mil em 1983. O número de desempregados, por sua vez, jamais esteve abaixo de 265 mil entre 1965 e 1980, sendo que em 1981 chegou a 820 mil (isso sem incluir o número de trabalhadores emigrantes). Se em 1973 o número de desempregados era de 381 mil, em 1985 esse número chegou a 1.039 mil, i.e., um aumento absoluto de 172,70\% em 12 anos (Wilczynski, 1983, p. 39; Woodward, 1995, p. 251-252, 377-378, 383-385).

Outro ponto importante da economia iugoslava era a inflação. Se no período 1976-1980 a média da inflação anual foi de 16,5\%, entre 1980 e 1984 a média foi de 39\%. Em 1984 a inflação média ficou em 54\%, enquanto em 1985 foi de 72\%, anunciando a dramática aceleração da inflação que teria lugar na segunda metade da década. Quanto ao regime cambial, a moeda do país, o dinar, passou de um regime de câmbio fixo para um regime de câmbio flexível com intervenção (dirty floating) em 1973. A taxa de câmbio foi continuamente desvalorizada desde a introdução desse regime, sendo que as desvalorizações se tornaram cada vez mais frequentes conforme a crise no balanço de pagamentos se desenvolvia (Payne, 1991, p. 351; Rocha, 1991, p. 2; Stojanovic, 2008, p. 215-233). 
Os últimos anos da década de 1980 foram de agravamento da crise econômica iugoslava.A situação do país deteriorou-se no que diz respeito aos principais indicadores macroeconômicos do país (taxa de crescimento, inflação, desemprego etc.), bem como na vida cotidiana, com o restabelecimento do racionamento de bens de consumo, algo desconhecido desde o início da década de 1950. As discórdias dentro da Liga dos Comunistas da Iugoslávia aceleraram-se rapidamente, levando a que as rivalidades entre os distintos grupos regionais ficassem cada vez mais acirradas. Com a morte de Tito em 1980, o arranjo institucional pulverizado da Iugoslávia não foi capaz de manter a unidade do país, que terminou se desintegrando em uma guerra civil. O sistema político surgido da Constituição de 1974 foi estabelecido para conciliar os interesses regionais, e não para que a Iugoslávia se tornasse um país com Repúblicas efetivamente integradas, econômica, social e politicamente. Pelo contrário, o resultado da carta de 1974 foi que o país se consolidou como uma Federação de Repúblicas e províncias autônomas relativamente isoladas e dominadas por castas burocráticas privilegiadas, as quais mantinham, muitas vezes, interesses contraditórios quando se analisava a situação da Iugoslávia como um todo (Crnobrnja, 1996, p. 83-86; Vladisavljevic, 2008, p. 207).

O crescimento dos movimentos nacionalistas no decênio dos 1980 não foi algo inédito na história iugoslava; algo semelhante havia ocorrido nos protestos de 1968 e em 1971 na "Primavera Croata", porém a repressão a esses movimentos foi possível, pois Tito era um elemento que possuía apoio político e militar em âmbito nacional. Após a sua morte, não havia nenhuma liderança na Iugoslávia capaz de ter uma autoridade nacional e manter o precário equilíbrio que mantinha a integridade territorial do país, já que o equilíbrio de poder entre essas Repúblicas estava baseado no fortalecimento das castas burocráticas locais, de modo que estas acumulassem privilégios diante do conjunto dos trabalhadores, e na condução personalista de Tito, o qual, desde a década de 1940, por um lado reprimia os movimentos nacionalistas e por outro evitava que os interesses das elites locais entrassem em rota de colisão. Por exemplo, uma de suas últimas medidas como figura principal do país foi estabelecer que a Presidência da Liga dos Comunistas da Iugoslávia fosse ocupada por representantes das Repúblicas (Sérvia, Eslovênia, Macedônia, Bósnia e Herzegovina, Montenegro e 
Croácia) e das províncias autônomas (Kosovo e Vojvodina) de acordo com um revezamento periódico (um ano), de maneira que oficiais de todas as regiões exercessem cargos de chefia em dado momento. $\mathrm{Na}$ ausência da liderança de Tito, os interesses nacionalistas terminaram por afirmar-se. A agravar isso tudo esteve a grave crise econômica que afetou o país durante o decênio de 1980. Com a exacerbação dessa crise e a agudização das contradições políticas e sociais, o país entrou em uma trajetória de acentuada instabilidade (Burg, 1986; Lendvai; Parcell, 1991).

A primeira crise de importante proporção após a morte de Tito verificou-se na Província de Kosovo em 1981. Os habitantes de Kosovo demandavam maiores recursos para a província, de forma a superar o atraso socioeconômico com respeito às demais regiões da Iugoslávia. A resposta do governo central da Iugoslávia foi a ocupação militar da província com cerca de 30 mil soldados. A partir desse conflito, exacerbou-se a situação de segregação étnica entre os distintos grupos que habitavam a província. A única área em que havia certa interação entre albaneses kosovares, sérvios, montenegrinos e os demais grupos era na administração local, por conta das pressões que o governo federal exercia sobre os oficiais locais. O consequente êxodo dos sérvios de Kosovo exaltou os ânimos nacionalistas na Sérvia, já que os sérvios eram importante minoria em todas as Repúblicas iugoslavas (além da Sérvia, onde eram, obviamente, maioria). Nas demais regiões a situação era similar: na Croácia, Eslovênia, Bósnia e Herzegovina, Macedônia e Montenegro, os respectivos movimentos nacionalistas e separatistas recrudesceram sua importância durante a década de 1980 (Burg, 1986, p. 170-173; Gjonça, 2001, p. 16; Pano, 1977, p. 40-41;Vickers, 2001, p. 203-207).

O período de Slobodan Milosevic como líder da Sérvia é ilustrativo do recrudescimento do nacionalismo na Iugoslávia. Em 1986, Milosevic tornou-se o líder da Liga dos Comunistas da Sérvia. Sua posição diante dos conflitos regionais era a de apoiar os sérvios, em especial nas províncias autônomas de Kosovo e Vojvodina e na República de Montenegro. Em 1987, a Liga dos Comunistas da Sérvia lançou uma campanha chamada "Revolução Antiburocrática" na Sérvia, a qual era não uma campanha contra o excesso de burocracia e os privilégios dos burocratas, mas sim era uma série de protestos organizados, em Kosovo,Vojvodina e Montenegro, pelos sérvios pró-Milosevic a fim de derrubar os dirigentes desses locais e substituí-los por aliados de Milosevic. Essa denominada "Revo- 
lução Antiburocrática" conseguiu seu intento e estabeleceu uma maioria pró-Milosevic tanto no Conselho da Presidência da Iugoslávia, como na Liga dos Comunistas da Iugoslávia, de forma tal que, a partir de então, Milosevic foi capaz de manipular essas duas instituições de acordo com seus interesses (Lendvai; Parcell, 1991; Prosic-Dvornic, 2000, p. 327-328; Tagliabue, 1989; Vladisavljevic, 2008).

Os conflitos nacionalistas na Iugoslávia intensificaram-se em um contexto de crise econômica. O Produto Material Líquido (PML) do país, que cresceu 3,5\% em 1986, teve nos anos subsequentes resultados modestos ou negativos (média de crescimento de -0,7\% entre 1987 e 1989). A razão para isso pode ser atribuída justamente ao desarranjo da situação econômica, política e social interna. Em 1990, o PML caiu mais de $8 \%$, sinalizando uma grave crise em que a Iugoslávia entraria. A taxa de inflação entrou em disparada no final da década, sendo um dos principais detonantes da insatisfação popular (chegou a 1.240\% em 1989). O motivo principal para esse fato é que as empresas do país possuíam dívidas em divisas, as quais cresciam conforme a moeda do país era desvalorizada para fins de ajuste do balanço de pagamentos; como as firmas eram livres para fixar seus preços, o repasse da desvalorização cambial aos preços finais era praticamente automático. E a taxa de desemprego, por sua vez, manteve-se acima dos 14,9\% durante todo o período, seguindo de perto a média da década de 1980, de 15,54\%. Cabe recordar que, além de apresentar uma elevada taxa de desemprego, a Iugoslávia era um país com alto contingente de emigrantes (Rocha, 1991, p. 2-4;VICFES, 1991, p. 58; Woodward, 1995, p. 385).

Diante da crise econômica, e com as mudanças políticas no Leste Europeu no fim da década de 1980, estabeleceu-se um consenso dentro do governo da Iugoslávia em favor da adoção formal do capitalismo. A política de não alinhamento já não fazia mais sentido com o enfraquecimento do campo socialista e os políticos passaram a adotar um discurso em prol da ocidentalização do país. Dentro desse contexto foi implementada uma reforma trabalhista facilitando as demissões e estabelecida a lei das privatizações em 1988, a qual permitiu que os gerentes das empresas não mais precisassem consultar os trabalhadores na tomada de suas decisões, bem como fez com que as empresas deixassem de ser consideradas "organizações de trabalho associado" (na prática essa lei marcou o fim do cooperativismo) (Woodward, 1995, p. 347-352). 
Entre 23 e 29 de março de 1989, uma série de protestos dos albaneses kosovares foi reprimida pelo governo sérvio, deixando um saldo de 24 mortos. Em seguida, Milosevic realizou um expurgo contra os albaneses kosovares tanto na Liga dos Comunistas, como no aparato de Estado, além de promover uma reforma na Constituição da Sérvia, que diminuiu substancialmente a autonomia de Kosovo. O resultado foi o recrudescimento da violência e da insatisfação popular na província. Os movimentos nacionalistas das demais regiões reagiram a isso aumentando a campanha pela independência e contra Milosevic, a quem alegavam querer criar uma "Grande Sérvia". Em particular, na Eslovênia esse movimento expansivo sérvio teve repercussões imediatas. Desde que Milan Kucan havia se tornado líder da Liga dos Comunistas da Eslovênia, essa República embarcou em uma política de liberação política, a qual entrou em conflito com as tendências centralizadoras da Sérvia sob comando de Milosevic e com o governo da Iugoslávia, dominado também por Milosevic. Em 1989, a Liga dos Comunistas da Eslovênia declarou o fim do monopartidarismo e alterou a Constituição da República, permitindo a saída da Eslovênia da Iugoslávia. Seguindo o exemplo dos eslovenos, a Croácia também encerrou o monopólio do poder político por parte dos comunistas e promoveu a realização de novas eleições. Nesse contexto de confrontação aberta das Repúblicas com o governo central, houve uma escalada das disputas políticas e da violência por toda a Iugoslávia, levando o país a uma guerra civil (Cowell, 1989; Thomas; Mikulan; Pavlovic, 2006, p. 5-6; Samary, 1995; Tagliabue, 1989;Vladisavljevic, 2008).

Em suma, vimos nesta seção do texto a trajetória econômica iugoslava após o choque do petróleo de 1973 até o decesso do socialismo no final da década de 1980. Investigamos como o país foi afetado pela alta dos preços das matérias-primas no cenário internacional e estudamos alguns dos motivos que levaram o país à guerra civil.

\section{Conclusões}

O objetivo deste trabalho foi investigar a trajetória econômica da Iugoslávia durante as mais de quatro décadas de tentativa de construção de uma sociedade socialista. Vimos neste trabalho que a Iugoslávia era um país caracterizado por um sistema de decisões políticas descentralizado 
e por uma economia cujas empresas eram cooperativas administradas pelos próprios trabalhadores. Ao contrário da União Soviética e de outros países socialistas, os iugoslavos relegavam à planificação econômica um papel secundário e confiavam nas forças de mercado como balizadora das decisões econômicas.

Suevos (1992, p. 127-132) argumenta que o socialismo de mercado iugoslavo apresentava falhas importantes, entre as quais o fato de que a livre disposição dos lucros por parte dos trabalhadores levava a uma dificuldade de estabilização da demanda efetiva no nível exigido para a manutenção do pleno emprego. De fato, como os trabalhadores possuem uma propensão marginal a consumir alta, a falta de uma racionalidade global para gerir o destino do excedente do país acarretava desproporções setoriais e pressões inflacionárias significativas. Além disso, as facilidades que as empresas encontravam para aceder ao crédito externo era outro fator que favorecia a negligência das empresas iugoslavas com a retenção do lucro como fonte de financiamento.

O dado fático é que o sistema de socialismo de mercado iugoslavo não foi capaz de superar as contradições advindas da pulverização da propriedade e da necessidade de algum tipo de racionalidade global que pudesse administrar e conciliar os interesses dos distintos grupos sociais do país. Se no plano econômico as principais características do país foram a inflação e o desemprego, no plano político a instabilidade administrativa redundou em uma guerra civil de sérias proporções. Os problemas nesse campo se agravaram após a morte de Tito em 1980, pois ele era uma figura com autoridade nacional e que foi capaz, através de medidas repressivas e de acordos com as elites locais, de manter a unidade do país por mais de 30 anos.

No que concerne ao contraste entre o "modelo iugoslavo" e as demais economias socialistas do Leste Europeu, a questão primordial é se as diferenças na forma jurídica da propriedade se traduziam efetivamente em mudanças qualitativas nas relações de produção. A resposta é não, pois a participação dos trabalhadores na vida econômica iugoslava em geral restringia-se à eleição dos conselhos operários e estava distante de uma situação em que eles controlassem suas condições de produção e determinassem democraticamente os objetivos e a organização do processo de trabalho. Da mesma forma que a expropriação dos capitalistas e o estabelecimento da propriedade estatal dos meios de produção não 
significam que as relações de produção tenham um caráter distinto das relações existentes sob o capitalismo, a mudança de propriedade estatal para cooperativa também não significa mudanças qualitativas para o trabalhador (Mandel, 1994, p. 65, 84-85, 120).

$\mathrm{Na}$ esfera social, por sua vez, a Iugoslávia apresentou ganhos sociais positivos no que diz respeito aos indicadores de educação, saúde, nutrição, habitação etc. Contudo, esses ganhos na esfera social foram obtidos com um alto custo, pois o regime social apresentava problemas graves, como o desemprego, a emigração e a presença de uma elite privilegiada com relação ao restante da população. Foram justamente todas essas contradições econômicas, políticas e sociais que levaram a Iugoslávia socialista à desintegração.A hipótese avançada neste artigo, de que tais contradições foram as causas principais para o decesso do socialismo iugoslavo, foi plenamente confirmada pela nossa investigação.

\section{Referências bibliográficas}

BAUCIC, Ivo. The effects of emigration from Yugoslavia and the problems of returning emigrant workers. The Hague: Martinus Nijhoff, 1972.

BICANIC, Rudolf. La via jugoslava al socialismo. Capitalismo e socialismo. Napoli: Liguori, 1976.

BURG, Steven L. Elite conflict in post-TitoYugoslavia. Soviet Studies, v. 38, n. 2, p. 170-193, 1986.

COWELL, Alan. Clamor in the East; party orthodoxy falters in a Yugoslav Republic. The New York Times, Nov. 30, 1989.

CRNOBRNJA, Mihailo. The Yugoslav drama. Montreal: McGill-Queen's University Press, 1996.

DENITCH, Bogdan. Limits and possibilities: the crisis of Yugoslav socialism and State socialist systems. Minneapolis: University of Minnesota Press, 1990.

DJILAS, Milovan. The new class: an analysis of the communist system. London: Thames and Hudson, 1957.

DOI - Directorate of Intelligence. Yugoslavia: key questions and answers on the debt crisis. An intelligence assessment. Washington: Central Intelligence Agency, 1984.

DYKER, David A. Yugoslavia: socialism, development and debt. London: Routledge, 1990.

FEJTO, François. Histoire des démocraties populaires. Tome 2: Après Staline. Paris: Seuil, 1969.

FLEMING, J. Marcus; SERTIC,Viktor R. The Yugoslav economic system. Staff Papers - International Monetary Fund, v. 9, n. 2, p. 202-225, July 1962. 
GJONÇA, Arjan. Communism, health and lifestyle: the paradox of mortality transition in Albania, 1950-1990. Westport: Greenwood Press, 2001.

GLIGOROV,Vladimir.Yugoslav economics facing reform and dissolution. In:WAGENER, Hans-Jürgen (ed.). Economic thought in communist and post-communist Europe. London: Routledge, 1998, p. 329-361.

GOMES, Luiz. Socialismo real: a experiência do Leste Europeu (1945-1990). Niterói: Programa de Pós-Graduação em Economia. Universidade Federal Fluminense, 2017 (Tese de Doutoramento).

GRUENWALD, Oskar. The Croatian spring, 1971: Socialism in one republic?. Nationalities Papers: The Journal of Nationalism and Ethnicity, v. 10, n. 2, p. 221-231, 1982.

HUNT, E. K.; SHERMAN, Howard J. Sistemas econômicos comparados: o mundo socialista. Petrópolis:Vozes, 1977.

LAMPE, John R.; PRICKETT, Russell O.; ADAMOVIC, Ljubisa S. Yugoslav-American economic relations since World War II. Durham: Duke University Press Books, 1990.

LENDVAI, Paul; PARCELL, Lis. Yugoslavia without Yugoslavs: the roots of the crisis. International Affairs, v. 67, n. 2, p. 251-261, Apr. 1991.

MANDEL, Ernest. El poder y el dinero. México: Siglo XXI, 1994.

MARCZEWSKI, Jean. ¿Crisis de la planificación socialista?. México: Fondo de Cultura Económica, 1975.

MCFARLANE, Bruce. Iugoslávia: perspectivas políticas atuais. In: DEUTSCHER, Isaac et al. Problemas e perspectivas do socialismo. Rio de Janeiro: Zahar, 1969, p. 104-129.

MIHAJLOVIC, Steven. Yugoslav Gastarbeiter: the guest who stayed for dinner. Northwestern Journal of International Law \& Business, v. 8, n. 1, spring, 1987.

MILLER, R. F. Developments inYugoslav agriculture - breaking the ideological barrier. East European Politics E Societies, v. 3, n. 3, 1989.

NEUBERGER, Egon; TYSON, Laura. The impact of international inflation on Yugoslavia. In: ROSEFIELDE, Steven (org.). World communism at the crossroads: military ascendancy, political economy, and human welfare. Boston: Martinus Nijhoff, 1980.

OIT - Organização Internacional do Trabalho. La autogestión en Yugoslavia. In: MANDEL, Ernest. Control obrero, consejos obreros, autogestión. México: Era, 1974 (1967), p. 312-326.

PANO, Nicholas C. Albania in the 1970s. Problems of Communism, v. 26, n. 6, p. 33-43, Nov.-Dec. 1977.

PAYNE, James E. Yugoslav price inflation: an empirical investigation. The Journal of Developing Areas, v. 25, n. 3, p. 395-404, 1991.

PEROVIC, Jeronim. The Tito-Stalin split: a reassessment in light of new evidence. Journal of Cold War Studies, v. 9, n. 2, p. 32-63, spring, 2007.

PROSIC-DVORNIC, Mirjana. Serbia: the inside story. In: HALPERN, Joel M.; KIDECKEL, David A. Neighbors at war: anthropological perspectives on Yugoslav ethnicity, culture, and history. Pennsylvania:The Pennsylvania State University Press, 2000, p. 316-335. 
RAJAK, Svetozar. Yugoslavia and the Soviet Union in the early Cold War: reconciliation, comradeship, confrontation, 1953-1957. London: Routledge, 2010.

ROCHA, Roberto de Rezende. Inflation and stabilization in Yugoslavia. Policy, Research, and External Affairs Working Papers. Washington (DC), World Bank, n. WPS 752, Macroeconomic adjustment and growth, 1991.

SAMARY, Catherine. Yugoslavia dismembered. New York: Monthly Review Press, 1995.

SINGLETON, Fred. A short history of the Yugoslav peoples. New York: Cambridge University Press, 1985.

STAAR, Richard. The communist regimes in Eastern Europe. 2. ed. Stanford: Hoover Institution Press, 1971.

STOJANOVIC, Biljana D. Exchange rate regimes of the Dinar 1945-1990: as assessment of appropriateness and efficiency. The experience of exchange rate regimes in Southeastern Europe in a historical and comparative perspective: Second Conference of the South-Eastern European Monetary History Network (SEEMHN).Vienna: OENB, 2008, p. 198-243.

SUEVOS, Ramom L. Socialismo e mercado. Notas de economia política. Santiago de Compostela: Laiovento, 1992.

TAGLIABUE, John. In a Yugoslav province, aflame for six days, the resentments still smolder. The New York Times, Apr. 4, 1989.

THOMAS, Nigel; MIKULAN, Krunoslav; PAVLOVIC, Darko. The Yugoslav wars (1): Slovenia \& Croatia 1991-95.V. 1. Oxford/New York: Osprey Publishing, 2006.

VANEK, Jaroslav.Yugoslav economic growth and its conditions. The American Economic Review, v. 53, n. 2, Papers and proceedings of the SEVENTY-FIFTH ANNUAL MEETING OF THE AMERICAN ECONOMIC ASSOCIATION, p. 555-561, May 1963.

VICKERS, Miranda. The Albanians: a modern history. New York: I. B. Tauris, 2001.

VIFCES -Vienna Institute for Comparative Economic Studies. COMECON data 1990. London: Palgrave Macmillan, 1991.

VLADISAVLJEVIC, Nebojsa. Serbia's antibureaucratic revolution. Milosevic, the fall of communism and nationalist mobilization. New York: Palgrave Macmillan, 2008.

V. M. Collectivization in Yugoslav agriculture. The World Today, v. 14, n. 2, p. 80-87, 1958.

VUCKOVIC, Milos. The recent development of the money and banking system of Yugoslavia. Journal of Political Economy, v. 71, n. 4, p. 363-377, Aug. 1963.

VUSKOVIC, Boris. Social inequality in Yugoslavia. New Left Review, n. 95, p. 26-45, Jan.-Feb. 1976.

WILCZYNSKI, J. Comparative industrial relations: ideologies, institutions, practices and problems under different social systems with special reference to socialist planned economies. London: The Macmillan Press, 1983.

WOODWARD, Susan L. Socialist unemployment: the political economy of Yugoslavia, 1945-1990. Princeton: Princeton University Press, 1995. 